\title{
Adverse Events in Patients with Blood Loss: A Pooled Analysis of 51 Clinical Studies from the Celecoxib Clinical Trial Database
}

\author{
G.H. Sands ${ }^{*}$, B. Shell and R. Zhang
}

Pfizer Inc, New York, NY, USA

\begin{abstract}
Background: Chronic use of nonsteroidal anti-inflammatory drugs (NSAIDs) is associated with an increased risk of gastrointestinal (GI) toxicity, including occult blood loss and the development of clinically significant anemia. The aim of this study was to investigate the clinical importance of clinically significant anemia/blood loss.

Methods: Pooled analysis of 51 blinded, controlled clinical studies $\geq 4$ weeks duration from the celecoxib clinical trial database, comparing celecoxib with NSAIDs or placebo. The adverse event (AE) profile in patients with clinically significant anemia/blood loss (defined as decreases in hemoglobin $\geq 2 \mathrm{~g} / \mathrm{dL}$ and/or hematocrit by $\geq 10 \%$ from baseline) was compared with the AE profile in patients without blood loss. Events that occurred in $<0.5 \%$ of patients were excluded from any comparisons. A threefold difference between groups was defined arbitrarily as being markedly higher.

Results: Overall 932/51,048 patients experienced clinically significant anemia/blood loss. Baseline demographics were similar in both groups. The incidence of AEs was markedly higher in patients who experienced clinically significant anemia/blood loss than those who did not; the majority of these differences were for GI AEs or their likely sequelae. The incidence of the following non-GI related AEs was also markedly higher in patients with blood loss: coronary artery disease $(1.2 \% v s 0.3 \%)$, myocardial infarction $(0.6 \%$ vs $0.2 \%)$, and pneumonia ( $1.7 \%$ vs $0.4 \%)$. Withdrawals due to AEs were more common among patients who experienced blood loss $(16.7 \%$ vs $10.4 \%)$.

Conclusions: Clinically significant anemia/blood loss may have clinically important adverse consequences beyond the sequelae previously known to be associated with NSAID-related GI effects.
\end{abstract}

Keywords: Blood loss, NSAIDs, GI.

\section{INTRODUCTION}

Nonsteroidal anti-inflammatory drugs (NSAIDs) are effective anti-inflammatory, antipyretic, and analgesic agents and are among the most widely prescribed drugs worldwide [1]. However, despite their accepted efficacy, it is well recognized that use of NSAIDs is associated with an increased risk of gastrointestinal (GI) damage, including overt bleeding, ulceration, occult blood loss, and the development of clinically significant anemia or blood loss $[2,3]$.

Recent evidence suggests some patients with mildly low or low-normal hemoglobin levels may have an increased risk of frailty, poor functional outcomes, hospitalization, and mortality [4-7]. In the recent Celecoxib versus Omeprazole and Diclofenac in Patients with Osteoarthritis and Rheumatoid Arthritis (CONDOR) randomized clinical trial [8] comparing the risk of GI events through the entire GI tract, clinically significant anemia or blood loss (predefined as a decrease in hemoglobin $\geq 2 \mathrm{~g} / \mathrm{dL}$ and/or hematocrit $\geq 10 \%$ points from baseline) was an important component of the composite primary GI endpoint [8]. Although blood loss is common in patients taking NSAIDs, few studies have been performed to determine the exact burden and clinical impact of this problem in patients taking NSAIDs or aspirin, or to determine whether blood loss is associated with other more

*Address correspondence to this author at the Pfizer Inc., 235 East 42nd Street, New York, NY, USA; Tel: +1 212733 6358; Fax: +1 212309 4481;

E-mail: George.Sands@pfizer.com clinically apparent adverse events (AEs). The objective of this analysis of pooled data from the celecoxib clinical trial database, including both patients treated with NSAIDs and placebo, was to investigate whether there is a clinically important difference in the $\mathrm{AE}$ profile of patients with clinically significant anemia or blood loss (predefined as a decrease in hemoglobin $\geq 2 \mathrm{~g} / \mathrm{dL}$ and/or hematocrit $\geq 10 \%$ points from baseline) compared with patients without such blood loss, regardless of treatment.

\section{MATERIALS AND METHODOLOGY}

\section{Study Design and Selection}

This was a retrospective, pooled analysis of 51 blinded, controlled clinical studies comparing celecoxib, a cyclooxygenase (COX)-2 selective NSAID, with other COX-2 selective and nonselective NSAIDs (nsNSAIDs) or placebo. To be eligible for inclusion, all clinical study reports (from Pfizer's Celecoxib Clinical Trial Database) must have been finalized by October 1, 2007; only randomized, double-blind controlled clinical trials with at least one celecoxib and one comparator (active or placebo) group, of a planned duration of daily treatment $\geq 4$ weeks, were included. All open-label extensions, crossover trials, and healthy volunteer studies were excluded. With these criteria applied, the resulting pooled dataset represents both male and female patients with osteoarthritis (OA), rheumatoid arthritis (RA), ankylosing spondylitis (AS), chronic low back pain, Alzheimer disease, and/or spontaneous adenomatous colorectal polyps. 


\section{Data Collection}

The primary end point was blood loss status (Y/N) defined as "Yes" if a patient had a $\geq 2 \mathrm{~g} / \mathrm{dL}$ hemoglobin drop and/or $\geq 10 \%$ hematocrit drop from baseline. This definition is consistent with the definition of clinically significant anemia or blood loss used (as a component of the composite primary GI end point) in both the CONDOR and Gastrointestinal Randomized Event and Safety Open-label NSAID Study (GI-REASONS) randomized clinical trials [8, 9]; the GI-REASONS study uses a prospectively randomized open-label blinded end point (PROBE) design (neither the CONDOR or GI-REASONS trials were included in this analysis, as they did not meet the clinical study report finalization date criterion).

To determine whether there were any clinically important consequences in patients with blood loss as defined above, the AE profile in patients with the blood loss status "Yes" was compared with the AE profile in patients without such blood loss. For the primary analysis, an AE was considered to be associated with blood loss if it occurred at any time during the time window from the last laboratory day normal hemoglobin/hematocrit values were recorded (before the first hemoglobin/hematocrit decrease), to the day hemoglobin/hematocrit values returned to normal or 30 days after the hemoglobin/hematocrit decrease, whichever occurred first (Fig. 1).

\section{Statistical Analysis}

The pooled analysis was performed on the safety population (all patients who were randomized in any of the included 51 clinical trials who took at least one dose of study medication and who had at least one safety assessment). Summary statistics were used to compare AE profiles (preferred AE terms based on Medical Dictionary for Regulatory Activities, MedDRA 11.0) in patients who had clinically significant blood loss ("Yes" for the primary end point) versus patients who did not ("No" for the primary end point). When comparing the percentage of patients with specific AEs between the groups, a threefold difference was defined arbitrarily as being "markedly higher"; any AE that occurred for $<0.5 \%$ of patients in both groups was excluded from treatment comparisons.

\section{RESULTS}

\section{Included Studies}

A total of 51 double-blind, randomized clinical trials met the criteria for inclusion and were pooled for this retrospective analysis (please see list of clinical trials,

Clinical Labs
Waseline Blood Loss
Criteria Not Met

including details on study duration and comparator treatments in Table 1). Study duration ranged from 4 weeks to 3 years. One study was event-driven, and thus patients in this study were exposed to study medication for different durations (median duration of 6-9 months), rather than for a protocol-defined time period.

\section{PATIENTS}

Generally, the majority of patients with clinically significant blood loss were approximately 1-year older than those without blood loss (mean age, 61 years vs 60 years, respectively; Table 2). Overall 932/51,048 (1.83\%) patients in the 51 studies described above experienced clinically significant anemia or blood loss (predefined by a decrease in hemoglobin $\geq 2 \mathrm{~g} / \mathrm{dL}$ and/or hematocrit $\geq 10 \%$ from baseline). The majority of patients in both groups had follow-up for $>6$ months, and baseline demographics were similar when patients with clinically significant blood loss were compared with those without (Table 2) such blood loss.

\section{End Points}

In general, patients with clinically significant blood loss had a higher incidence of AEs than those who did not $(66 \%$ and 58\%, respectively; Table 3 ). The majority of the difference between groups could be accounted for by AEs representing GI disorders or their likely sequelae. The specific AEs of this type that were markedly increased (defined as greater than threefold difference) for patients with clinically significant blood loss versus those without it were: gastric ulcer $(1.5 \%$ vs $0.2 \%$, respectively); GI hemorrhage $(0.8 \%$ vs $<0.1 \%)$; esophageal ulcer $(0.5 \%$ vs $<0.1 \%$ ); melena ( $1.3 \%$ vs $0.1 \%)$; anemia ( $8.8 \%$ vs $0.6 \%$ ); increase in blood creatinine $(1.7 \%$ vs $0.4 \%)$; decrease in hemoglobin ( $8.9 \%$ vs $0.2 \%)$; decrease in hematocrit $(10.4 \%$ vs $0.5 \%)$; decrease in red blood cell count $(0.8 \%$ vs $<0.1 \%)$; and hematochezia ( $1.0 \%$ vs $0.3 \%)$.

However, the incidence of the following non-GI related $A E S$ was also markedly higher in patients with clinically significant blood loss compared with patients without such blood loss: coronary artery disease $(1.2 \%$ vs $0.3 \%$, respectively), myocardial infarction $(0.6 \%$ vs $0.2 \%)$, and pneumonia ( $1.7 \%$ vs $0.4 \%)$.

Withdrawals due to AEs were more common among patients who had clinically significant blood loss $(17 \%)$ than among those who did not (10\%) have such blood loss.

\section{DISCUSSION}

The findings of this retrospective pooled analysis support the hypothesis that a decrease in hemoglobin $\geq 2 \mathrm{~g} / \mathrm{dL}$ and/or

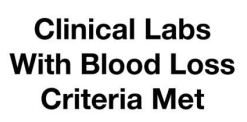

Clinical Labs

With Blood Loss

Criteria Not Met 
Table 1. Clinical Studies Included in the Pooled Analysis

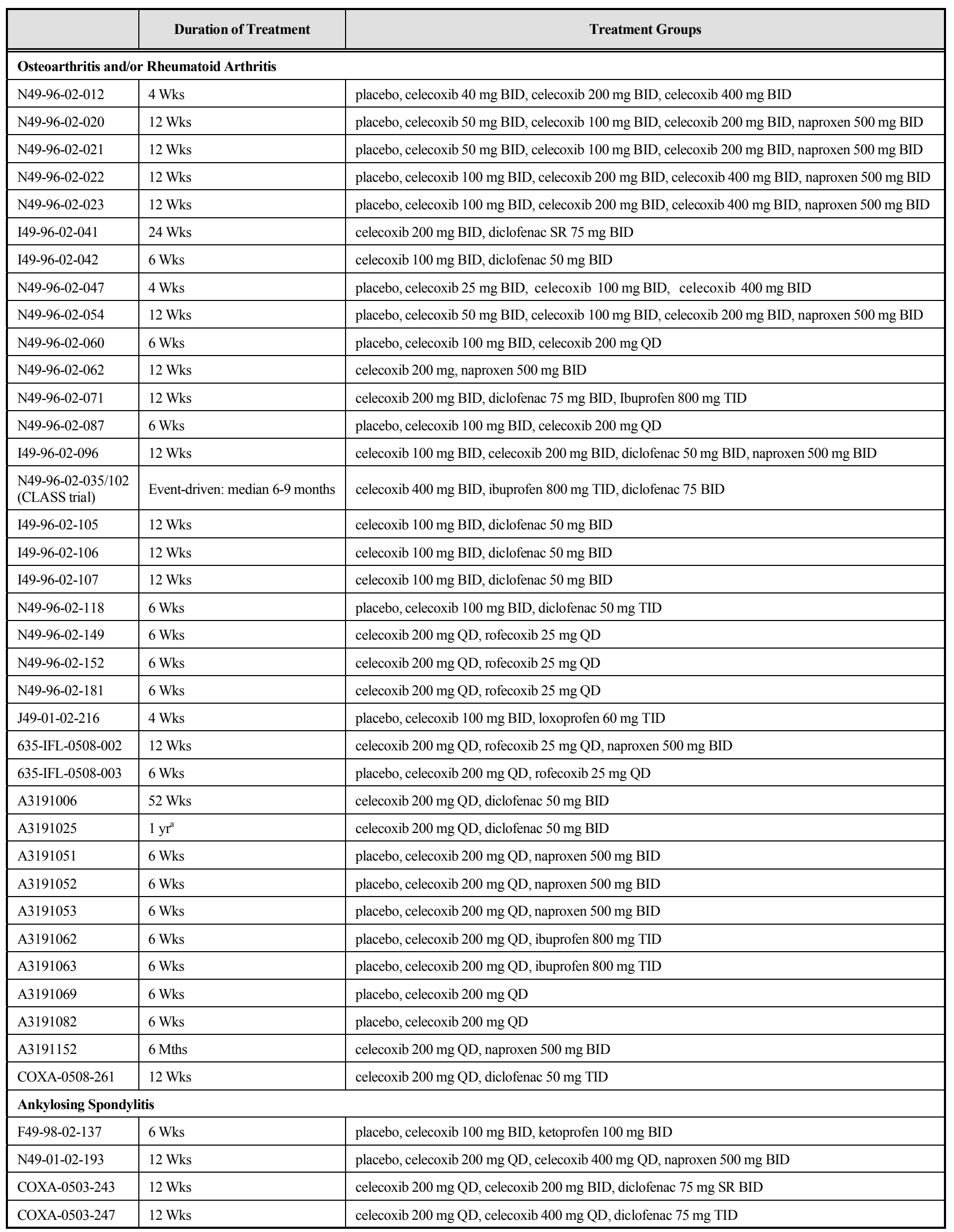


(Table 1) contd.....

\begin{tabular}{|c|c|c|}
\hline & Duration of Treatment & Treatment Groups \\
\hline \multicolumn{3}{|c|}{ Chronic Low Back Pain } \\
\hline J49-01-02-217 & $4 \mathrm{Wks}$ & celecoxib $100 \mathrm{mg}$ BID, loxoprofen $60 \mathrm{mg}$ TID \\
\hline COXA-0508-244 & $12 \mathrm{Wks}$ & placebo, celecoxib $200 \mathrm{mg}$ QD \\
\hline COXA-0508-245 & $12 \mathrm{Wks}$ & placebo, celecoxib $200 \mathrm{mg}$ QD \\
\hline COXA-0508-269 & $12 \mathrm{Wks}$ & placebo, celecoxib $200 \mathrm{mg}$ QD, celecoxib $200 \mathrm{mg}$ BID \\
\hline A3191174 & $4 \mathrm{Wks}$ & celecoxib 200 mg BID, loxoprofen $60 \mathrm{mg}$ TID \\
\hline \multicolumn{3}{|l|}{ Alzheimer Disease } \\
\hline IQ5-97-02-001 & $52 \mathrm{Wks}$ & placebo, celecoxib $200 \mathrm{mg}$ BID \\
\hline EQ5-98-02-002 & $3 \mathrm{yr}^{\mathrm{a}}$ & placebo, celecoxib $200 \mathrm{mg}$ BID \\
\hline NQ5-98-02-005 & $4 \mathrm{Wks}$ & placebo, celecoxib $200 \mathrm{mg}$ BID \\
\hline \multicolumn{3}{|c|}{ Spontaneous Colorectal Adenomatous Polyps } \\
\hline NQ4-00-02-011 & $12 \mathrm{Wks}^{\mathrm{a}}$ & placebo, celecoxib $100 \mathrm{mg}$ BID, celecoxib $200 \mathrm{mg}$ BID, celecoxib $400 \mathrm{mg}$ BID \\
\hline EQ4-00-02-018 & $3 y^{a}$ & placebo, celecoxib $400 \mathrm{mg}$ QD \\
\hline IQ4-99-02-005 & $3 y^{a}$ & placebo, celecoxib $200 \mathrm{mg}$ BID, celecoxib $400 \mathrm{mg}$ BID \\
\hline
\end{tabular}

For this analysis, blood loss was predefined as a decrease in hemoglobin $\geq 2 \mathrm{~g} / \mathrm{dL}$ and/or hematocrit $\geq 10 \%$ from baseline.

QD: once daily; BID: twice daily; TID: three times daily.

${ }^{a}$ Treatment with study medication was suspended or terminated early.

hematocrit $\geq 10 \%$ points from baseline represents a clinically relevant event. As might be expected, hematologic observations of this type may be associated with pathophysiologic processes that result in either overt bleeding (e.g. GI hemorrhage and melena) or lesions that may reasonably be expected to account for bleeding that cannot be observed directly (e.g. gastric and esophageal ulcers). However, pathophysiologic states resulting from such blood loss, for example a reduction in oxygen-carrying capacity or a compromised immune system, may explain the increased incidence of particular non-GI AEs observed in patients with blood loss (e.g. myocardial infarction, coronary artery disease, and pneumonia). As these kinds of events are relatively rare in clinical trial populations, it is not clear whether the inability to detect other non-GI events of related etiology in this current analysis was a result of underpowering due to limited sample size or due to more mechanistic effects.

The goal of this analysis was to better understand the clinical implications of a decrease in hemoglobin $\geq 2 \mathrm{~g} / \mathrm{dL}$ and/or hematocrit $\geq 10 \%$ points from baseline over time. Both the CONDOR [8,9] and GI-REASONS [9] trials included this measure of clinically significant blood loss as a component of the predefined composite primary GI end point for "Clinically Significant Upper and Lower GI Events." In contrast to the current analysis, the end point, in these two clinical trials, was adjudicated by an independent expert blinded panel to be of confirmed or likely GI source. We now know the majority of the primary end point events in CONDOR were adjudicated as meeting this prespecified definition of clinically significant blood loss rather than the more traditional end point for evaluation of GI effects for NSAIDs - GI perforations, ulcers, or overt bleeds (PUBs), or "ulcer complications" [8]. Thus, the results of this current respective analysis of data from 51 clinical studies may help to establish the clinical importance of blood loss events that are not readily identifiable as PUBs.
Table 2. Baseline Demographics and Characteristics of Patients Included in the Pooled Analysis

\begin{tabular}{|c|c|c|}
\hline & $\begin{array}{l}\text { Patients with Blood Loss } \\
\qquad(\mathrm{n}=932)\end{array}$ & $\begin{array}{l}\text { Patients without Blood Loss } \\
\qquad(\mathrm{n}=\mathbf{5 0 , 1 1 6 )}\end{array}$ \\
\hline \multicolumn{3}{|l|}{ Age, $y$} \\
\hline Mean & 61 & 60 \\
\hline Median & 61 & 61 \\
\hline Range & $21-91$ & $17-96$ \\
\hline \multicolumn{3}{|l|}{ Race, n (\%) } \\
\hline White & $746(80)$ & $38,166(76)$ \\
\hline Black & $54(5.8)$ & $3218(6.4)$ \\
\hline Asian & $102(11)$ & $5518(11)$ \\
\hline Other & $29(3)$ & $2970(66)$ \\
\hline Missing & $1(0.1)$ & $244(0.5)$ \\
\hline \multicolumn{3}{|l|}{ Sex, n (\%) } \\
\hline Female & 547 (59) & $32,861(66)$ \\
\hline Male & $385(41)$ & $17,255(34)$ \\
\hline \multicolumn{3}{|l|}{ Weight, kg } \\
\hline Female, n (\%) & $544(58)$ & $32,778(65)$ \\
\hline Mean & 72 & 76 \\
\hline Median & 69 & 73 \\
\hline Range & $36-163$ & $32-250$ \\
\hline \multicolumn{3}{|l|}{ Weight, kg } \\
\hline Male, n (\%) & $383(41)$ & $17,225(34)$ \\
\hline Mean & 87 & 88 \\
\hline Median & 86 & 85 \\
\hline Range & $48-158$ & $35-232$ \\
\hline
\end{tabular}


Table 3. Adverse Events (AEs) in Patients with Clinically Significant Anemia/Blood Loss ${ }^{\mathrm{a}}$ Versus those Without (Threshold $\geq 0.5 \%$ )

\begin{tabular}{|c|c|c|}
\hline AEs, $n(\%)^{b}$ & $\begin{array}{l}\text { Patients with } \\
\text { Blood Loss } \\
(\mathrm{n}=932)\end{array}$ & $\begin{array}{l}\text { Patients without } \\
\text { Blood Loss } \\
(\mathrm{n}=\mathbf{5 0 , 1 1 6})\end{array}$ \\
\hline Any AE & $612(66)$ & $29,222(58)$ \\
\hline \multicolumn{3}{|l|}{ GI-Related AEs } \\
\hline Gastric ulcer & $14(1.5)$ & $101(0.2)$ \\
\hline GI hemorrhage & $7(0.8)$ & $33(<0.1)$ \\
\hline Esophageal ulcer & $5(0.5)$ & $24(<0.1)$ \\
\hline Melena & $12(1.3)$ & $57(0.1)$ \\
\hline \multicolumn{3}{|l|}{ Potential GI-Related AEs } \\
\hline Anemia & $82(8.8)$ & $317(0.6)$ \\
\hline Increase in blood creatinine & $16(1.7)$ & $207(0.4)$ \\
\hline Decrease in hemoglobin & $83(8.9)$ & $120(0.2)$ \\
\hline Decrease in hematocrit & $97(10.4)$ & $228(0.5)$ \\
\hline Decrease in red blood cell count & $7(0.8)$ & $23(<0.1)$ \\
\hline Hematochezia & $9(1.0)$ & $126(0.3)$ \\
\hline \multicolumn{3}{|l|}{ Non-GI-Related AEs } \\
\hline Coronary artery disease & $11(1.2)$ & $144(0.3)$ \\
\hline Myocardial infarction & $6(0.6)$ & $99(0.2)$ \\
\hline Pneumonia & $16(1.7)$ & $202(0.4)$ \\
\hline
\end{tabular}

${ }^{a}$ Markedly higher, i.e. threefold difference between treatment groups in the incidence of AEs.

${ }^{\mathrm{b}}$ Preferred terms based on MedDRA 11.0.

The findings of the CONDOR trial [8] and the previous Celecoxib Long-term Arthritis Safety Study (CLASS) [10] suggest clinically significant blood loss, as defined in the current analysis and the CONDOR trial, is a consequence of the effects of NSAIDs on GI physiology. In both CONDOR and CLASS, decreases in hemoglobin $\geq 2 \mathrm{~g} / \mathrm{dL}$ occurred similarly over time, despite differences in trial design, and were prevalent in these patients treated with NSAIDs [11]. In another recent study of 892 randomized participants with chronic knee pain, who were treated with either nonprescription doses of ibuprofen and acetaminophen or two different non-prescription dose combinations of ibuprofen/acetaminophen, up to approximately $18 \%$ of all participants had decreases of hemoglobin $\geq 2 \mathrm{~g} / \mathrm{dL}$ in the various treatment groups, supporting the clinical relevance of this safety measure [12]. Of these three trials for which published data are available, CLASS and CONDOR had decreases in hemoglobin $\geq 2 \mathrm{~g} / \mathrm{dL}$ prespecified for analysis; in the CONDOR trial (but not the CLASS trial) these decreases were also adjudicated for association with GI sources.

Strand et al., analyzed 14 randomized clinical trials from the celecoxib database, including more than 14,000 arthritis patients, and discovered treatment in patients with decreases in hemoglobin $\geq 2 \mathrm{~g} / \mathrm{dL}$ was associated with no improvement in physical function, contrasting to those patients with no decreases in hemoglobin. Following treatment, the latter group of patients demonstrated improvements in physical functioning, as assessed by the Medical Outcomes Study Short Form with 36 questions (SF-36) [13].

\section{STRENGTHS/LIMITATIONS}

One of the strengths of this analysis was the inclusion of more than 51,000 patients with active disease-OA, RA, or AS - giving a robust sample size. A second strength, was the use of the prespecified definition of clinically significant anemia or blood loss (previously used in both the CONDOR and GI-REASONS randomized clinical trials). However, we should be cautious when interpreting these findings as even in this analysis population of more than 51,000 patients, some of the specific AEs examined occurred in too few patients to provide the most robust information. Furthermore, analysis of trials solely from the celecoxib trial database might exclude relevant trials conducted elsewhere, and while many of the randomized controlled trials included in this pooled analysis had a similar study structure, they were not identical, which could potentially have introduced bias.

\section{CONCLUSION}

Clinically significant anemia or blood loss, defined as decreases in hemoglobin $\geq 2 \mathrm{~g} / \mathrm{dL}$ and/or hematocrit by $\geq 10 \%$ from baseline, may have clinically important adverse consequences beyond the sequelae previously known to be associated with NSAID-related GI effects. The discovery of gastric and esophageal ulcers in the group of patients with a markedly higher incidence of clinically significant blood loss suggests possible occult GI bleeding from this source. The markedly increased incidence for some non-GI related $A E$ terms suggests clinically significant blood loss may be especially important in those patients needing all of their oxygen-carrying capacity. Further studies are required to better understand the clinical importance of clinically significant anemia or blood loss.

\section{TRIAL REGISTRATION}

Current controlled trials N499602012, N499602020, N499602021, N499602022, N499602023, I499602041, I499 602042, N499602047, N499602054, N499602060, N49960 2062, N499602071, N499602087, I499602096, N4996020 35/102, I499602105, I499602106, I499602107, N4996021 18, N499602149, N499602152, N499602181, J490102216, 635IFL0508002, 635IFL0508003, A3191006, A3191025, A3191051, A3191052, A3191053, A3191062, A3191063, A3191069, A3191082, A3191152, COXA0508261, F49980 2137, N490102193, COXA0503243, COXA0503247, J4901 02217, COXA0508244, COXA0508245, COXA0508269, A3191174, IQ59702001, EQ59802002, NQ59802005, NQ40002011, EQ40002018, and IQ49902005.

\section{ACKNOWLEDGEMENTS AND FUNDING}

The study was sponsored by Pfizer Inc. All authors were full-time employees at the time the manuscript was written. Editorial support was provided by L. Prevost, of PAREXEL, and was funded by Pfizer Inc. 


\section{CONFLICT OF INTEREST}

GEORGE H. SANDS - Pfizer Inc. full-time employee and shareholder.

BRITON SHELL - Pfizer Inc. full-time employee and shareholder.

RICHARD ZHANG - Pfizer Inc. full-time employee and shareholder.

\section{AUTHOR'S CONTRIBUTIONS}

GEORGE H. SANDS - design of study, analysis and interpretation of the data, critical revision/drafting of the manuscript, final approval to submit.

BRITON SHELL - design of study, analysis and interpretation of the data, critical revision/drafting of the manuscript, final approval to submit.

RICHARD ZHANG - statistical analysis and interpretation, critical revision/drafting of the manuscript, final approval to submit.

\section{ABBREVIATIONS}

$\begin{array}{lll}\mathrm{AE} & = & \text { Adverse event } \\ \mathrm{AS} & = & \text { Ankylosing spondylitis } \\ \mathrm{CLASS} & = & \text { Celecoxib Long-term Arthritis Safety } \\ \mathrm{Study} & = & \text { Twice daily } \\ \mathrm{BID} & = & \text { Celecoxib versus Omeprazole and } \\ \mathrm{CONDOR} & \text { Diclofenac in Patients with Osteoarthritis } \\ & \text { and Rheumatoid Arthritis } \\ \mathrm{COX} & = & \text { Cyclooxygenase } \\ \mathrm{GI} & = & \text { Gastrointestinal } \\ \mathrm{GI}-\mathrm{REASONS}= & \text { Gastrointestinal Randomized Event and } \\ & \text { Safety Open-label NSAID Study } \\ \text { MedDRA } & = & \text { The Medical Dictionary for Regulatory } \\ & \text { Activities } \\ \text { NSAIDs } & = & \text { Nonsteroidal anti-inflammatory drugs } \\ \text { OA } & = & \text { Osteoarthritis } \\ \text { PROBE } & = & \text { Prospectively randomized open-label } \\ & & \text { blinded end point }\end{array}$

PUBs

QD

RA

SF-36

TID

\section{REFERENCES}

[1] Scheiman JM, Hindley CE. Strategies to optimize treatment with NSAIDs in patients at risk for gastrointestinal and cardiovascular adverse events. Clin Ther 2010;32: 667-77.

[2] Allison MC, Howatson AG, Torrance CJ, Lee FD, Russell RI. Gastrointestinal damage associated with the use of nonsteroidal antiinflammatory drugs. N Engl J Med 1992; 327: 749-54.

[3] Lanas A, Sopena F. Nonsteroidal anti-inflammatory drugs and lower gastrointestinal complications. Gastroenterol Clin North Am 2009; 38: 333-52.

[4] Eisenstaedt R, Penninx BW, Woodman RC. Anemia in the elderly: current understanding and emerging concepts. Blood Rev 2006; 20: 213-26.

[5] Penninx BW, Pluijm SMF, Lips P, et al. Late-life anemia is associated with increased risk of recurrent falls. J Am Geriatr Soc 2005; 53: 2106-11.

[6] Penninx BW, Pahor M, Woodman RC, Guralnik JM. Anemia in old age is associated with increased mortality and hospitalization. J Gerontol A Biol Sci Med Sci 2006; 61A: 474-9.

[7] Chaves PH, Xue QL, Guralnik JM, Ferrucci L, Volpato S, Fried LP. What constitutes normal hemoglobin concentration in community-dwelling disabled older women? J Am Geriatr Soc 2004; 52: 1811-6.

[8] Chan FK, Lanas A, Scheiman J, Berger MF, Nguyen H, Goldstein JL. Celecoxib versus omeprazole and diclofenac in patients with osteoarthritis and rheumatoid arthritis (CONDOR): a randomised trial. Lancet 2010; 376: 173-9.

[9] Chan FK, Cryer B, Goldstein JL, et al. A novel composite endpoint to evaluate the gastrointestinal (GI) effects of nonsteroidal antiinflammatory drugs through the entire GI tract. J Rheumatol 2010; 37: 167-74.

[10] Silverstein FE, Faich G, Goldstein JL, et al. Gastrointestinal toxicity with celecoxib vs nonsteroidal anti-inflammatory drugs for osteoarthritis and rheumatoid arthritis: the CLASS study: a randomized controlled trial. Celecoxib Long-term Arthritis Safety Study. JAMA 2000; 284: 1247-55.

[11] Goldstein JL, Chan FK, Lanas A, et al. Haemoglobin decreases in NSAID users over time: an analysis of two large outcome trials. Aliment Pharmacol Ther 2011; 34: 808-16.

[12] Doherty M, Hawkey C, Goulder M, et al. A randomised controlled trial of ibuprofen, paracetamol or a combination tablet of ibuprofen/paracetamol in community-derived people with knee pain. Ann Rheum Dis 2011; 70: 1534-41.

[13] Strand V, Cryer B, Luo X, et al. Effect of blood loss on physical function in arthritis patients: a pooled analysis. Health Outcomes Res Med 2011; 2: e27-e38.

This is an open access article licensed under the terms of the Creative Commons Attribution Non-Commercial License (http://creativecommons.org/licenses/by-nc/ 3.0/) which permits unrestricted, non-commercial use, distribution and reproduction in any medium, provided the work is properly cited. 